\title{
Molecular evidence for association of papaya ringspot virus with papaya from North East Hill region of India
}

\author{
HEMAVATI RANEBENNUR ${ }^{*}$, SUSHEEL KUMAR SHARMA ${ }^{2}$, PINKI PAL ${ }^{1}$ and S.V. NGACHAN ${ }^{3}$ \\ ${ }^{1}$ ICAR Research Complex for NEH Region, Tripura Centre, Lembucherra, Agartala, West Tripura 799 210, Tripura, India \\ 2ICAR Research Complex for NEH Region, Manipur Centre, Lamphelpat, Imphal 795 004, Manipur, India \\ ${ }^{3}$ ICAR Research Complex for NEH Region, Umroi Road, Umiam793 103, Meghalaya, India
}

Received: 24 April 2017/ Accepted: 31 May 2017/ Published online: 31 May 2017

(C) Indian Phytopathological Society 2017

\begin{abstract}
Papaya ringspot virus (PRSV) is a major bottleneck in papaya production globally. The incidence of PRSV was as high as $51 \%$ in West Tripura district of Tripura followed by Imphal West of Manipur (41.6\%) exhibiting the typical symptoms of yellowing, vein clearing, mottling, severe blistering with distorted leaves and concentric rings on the fruits. The papaya cultivars RCTP 1, Red Lady and Manipur local exhibited typical symptoms of PRSV under sap inoculation. The typical flexuous particles of size $800 \times 12 \mathrm{~nm}$ were observed in the electron microscope. The amplicons of size 350 bp were observed in RT-PCR using the primers derived from the conserved NIb region of Potyvirus genome. Two PRSV isolates from North East India (PRSV-Mnp1 and PRSV-Trp1) had maximum identity of 83.1 to $84 \%$ with PRSV isolates from Thailand, Taiwan and Korea for conserved NIb genomic region. Phylogenetically PRSV isolates from North East India segregated to a distinct cluster compared to other isolates from different papaya growing regions of the world. It is the first molecular evidence for the association of PRSV with papaya from North East Hill region of India.
\end{abstract}

Keywords: NIb region, North East India, papaya ringspot virus, papaya, RT-PCR

Papaya (Carica papaya) is mainly grown in tropical region and fruit has high nutritive and medicinal value. Papaya is cultivated in an area of 1.26 lakh ha and with production of 55.08 lakh tonnes. Globally India ranks first in papaya production with annual production of 5,508 metric tonnes (NHB, 2015). In North East India, area under papaya is 0.1682 lakh ha and annual production is 2.6283 lakh tonnes (NHB, 2015). Several fungal and viral diseases attack papaya and among the viral diseases, papaya ringspot is an important disease causing significant losses to the crop yield and has become a major threat to the papaya cultivation throughout India by rendering papaya orchards unproductive (Varma, 1988). Associated virus i.e. papaya ringspot virus (PRSV) was first reported in the year 1948 (Capoor and Varma, 1948). PRSV leads to crop yield losses upto $85-90 \%$ (Hussain and Varma, 1994). PRSV belongs to super kingdom viridae, kingdom ss RNA, family Potyviridae, genus Potyvirus and species Papaya ringspot virus. Virus particles are flexuous rod measuring 760-800 nm X 12 $\mathrm{nm}$ (Yeh et al., 1998). The virion contains a positive sense, single stranded RNA genome of approximately $10.3 \mathrm{~kb}$ length, surrounded by a coat protein (CP) and the molecular weight of single coat protein subunit is $36 \mathrm{kDa}$ (Yen et al., 1992). PRSV is transmitted by several species of aphids in a non-persistent mode and mainly infect cucurbits and papaya. PRSV has two biotypes; Type-P (PRSV-P) infecting cucurbits and papaya, and Type W

${ }^{*}$ Corresponding author: hemaiari @ gmail.com
(PRSV-W) infecting only cucurbits and not papaya (Purcifull et al., 1984). PRSV infection leads to diverse kind of symptoms on papaya (Brunt, 1996). The most prominent kind of symptoms associated with PRSV infection are leaf mottling and malformation, ring spots on fruits with prominent streaks on stems and petioles of plants. This leads to overall stunting of the plants making it unproductive and eventually plant dies (Tripathi et al., 2008).

Several strategies have been adopted for management of PRSV; however complete control has not been achieved (Tripathi et al., 2008). Selection and use of PRSV strains having attenuated pathogenicity in cross-protection based management of PRSV has been attempted (Fermin et al., 2010). In the last decade, a major focus has been on the use of RNA interference (RNAi) technology in developing resistance to PRSV (Azad et al., 2014; Krubphachaya et al., 2007). For employing these strategies accurate detection of associated virus and its molecular characterization is a prerequisite. Molecular diagnosis of PRSV ( $P$ and $W$ ) has been initially achieved by targeting coat protein (CP) region amplification by reverse transcription-polymerase chain reaction (RT-PCR) (Jain, 1998; Kumar, 2003). However, mutations in the primer binding sites may lead to false negative results, hence primers targeting more conserved genomic regions like $\mathrm{NIb}$ has been employed (Gulsiri et al., 2003; Sharma, 2004). Reports on the detection and molecular characterization of PRSV from 
different geographical regions of India are available, however, no systematic study on the occurrence, incidence and molecular characterization of PRSV from North Eastern Hill (NEH) region of India have been undertaken. With this background, the present study was undertaken to assess the incidence papaya ringspot disease and confirmation of association of PRSV in infected papaya through RT-PCR technique.

\section{MATERIALS AND METHODS}

\section{Incidence of PRSV in Manipur and Tripura}

A roving survey was conducted in four districts of Tripura and four districts of Manipur. In each district, different places were visited where papaya was cultivated and during the survey observations on percent disease incidence, stage of the crop and symptoms were recorded. Percent disease incidence was calculated as:

Percent disease incidence $=$ Number of plants infected/ Total number of plants observed X 100

\section{Mechanical transmission}

The mechanical transmission was undertaken using papaya cultivars RCTP-1, Red Lady and some Local varieties of Papaya of Manipur and Chenopodium amaranticolor. The PRSV infected leaf samples were finely ground in a snap-chilled mortar and pestle using sodium phosphate buffer $\mathrm{pH} 7.5(1: 1 \mathrm{w} / \mathrm{v})$. The finely ground sap was filtered through double layered cheesecloth and filtrate was mixed with a pinch of celite Powder (600 mesh). For sap inoculation a piece of sterile cotton pad dipped in filtrate was rubbed unidirectional from petiole towards the margin of the leaves on the test plants (20 days old). The leaves were supported with a piece of cardboard under the lower surface to avoid injury. The inoculated leaves were washed with a jet of water to remove traces of celite. The plants were labeled and kept for observation under insect-proof conditions and were observed at weekly intervals post-inoculation.

\section{Electron microscopy}

Sodium Phosphate buffer 1:1 (w/v) was used for macerating $100 \mathrm{mg}$ of infected leaf sample. The macerated solution was centrifuged at $1200 \mathrm{rpm}$ for 5 minutes and the clear supernatant was separated. Few drops of this clear solution was placed on copper grids coated with formavar. After 5 minutes, these grids were washed with double distilled water. The staining was done with $2 \%$ uranyl acetate and excess stain was removed. The grids were examined in the transmission electron microscope (JEOL $100 \mathrm{CX}-11$ ) at Advanced Centre for Plant Virology, Division of Plant Pathology, ICAR-IARI, New Delhi.

\section{Reverse transcription-polymerase chain reaction (RT- PCR)}

The total RNA preparations of healthy and symptomatic leaf tissue $(100 \mathrm{mg})$ of field collected samples of two representative isolates (PRSV-Mnp1 from Manipur and PRSV-Trp1 from Tripura) was extracted using RNeasy Plant Mini kit following the manufacturer's protocol (Qiagen Inc.). Isolated RNA was incubated at 70ㄷ for 5 min and snap-cooled before using as template. One step RT-PCR was performed in the same tube following standard method. The PCR reaction mixture $(100 \mu \mathrm{l})$ contained $2 \mu \mathrm{l}$ of primers (100 pmol/ $\mu \mathrm{l}) \mathrm{NIb} 2 \mathrm{~F}$ and NIb 3R (Zheng et al., 2008), 5 units RNase inhibitor (Invitrogen), 10 units of reverse transcriptase (Qiagen Inc.), 5 units Taq polymerase (Qiagen Inc.), 1X PCR buffer, $10 \mathrm{mM}$ dithiotheritol, $1 \mathrm{XQs}$ solution and $10 \mu \mathrm{M}$ each of the dNTPs. The amplification conditions were: one cycle of $45 \mathrm{~min}$ at $42^{\circ} \mathrm{C}, 40$ cycles of $30 \mathrm{~s}$ at $94^{\circ} \mathrm{C}, 2$ min at $46^{\circ} \mathrm{C}$ and $1 \mathrm{~min}$ at $72^{\circ} \mathrm{C}$ and one cycle of $5 \mathrm{~min}$ at $72^{\circ} \mathrm{C}$. Following PCR, $10 \mu \mathrm{l}$ of reaction products was analysed on $1 \%$ agarose gel and visualized using UV transilluminator.

\section{Cloning and sequencing of amplicons}

PCR amplified amplicons were gel purified using commercial kit (Qiagen Inc.) and cloned in pGEM-T Easy vector (Promega). These clones were sequenced bidirectionally at commercial facility (Xcelris Genomics, Ahmedabad, India). Sequences were initially analyzed using NCBI-BLAST.

\section{In silico sequence analysis}

The sequences of two PRSV isolates were compared with the corresponding partial NIb nucleotide sequences of diverse PRSV isolates (both $P$ type and $W$ type) reported from different geographical locations of the world (accession number of PRSV isolates are mentioned in Fig. 3, 4). Sequence identity matrix for pairwise combination of aligned sequences was calculated with BioEdit Sequence Alignment Editor 7.1.3 (Hall, 1999). Phylogenetic analysis was performed using MEGA6 (Tamura et al., 2013) and p-distance method was used to compute evolutionary distances. Trees were constructed with phylogeny test by bootstrapping 1000 replicates. The evolutionary history was inferred by neighbor-joining (NJ) methods available in MEGA6.

\section{RESULTS AND DISCUSSION}

The PRSV incidence was recorded in all the districts of Tripura and Manipur which were surveyed for the disease. The typical symptoms of yellow mottling, vein-clearing of young leaves, blistering and leaf distortion were observed. Dark-green streaks and rings in the leaf stalks as well as stems of plants were observed in some parts of Tripura. Typical concentric rings along with C-shaped markings and mixture of light and darker green colour on fruits (mosaic-like symptoms) were also observed in some cases (Fig. 1).

The disease incidence varied from $22 \%$ to $51 \%$. The incidence was highest in papaya orchards of West Tripura district $(51 \%)$ followed by Imphal West $(41.6 \%)$. Two selected PRSV isolates from Tripura and Manipur 


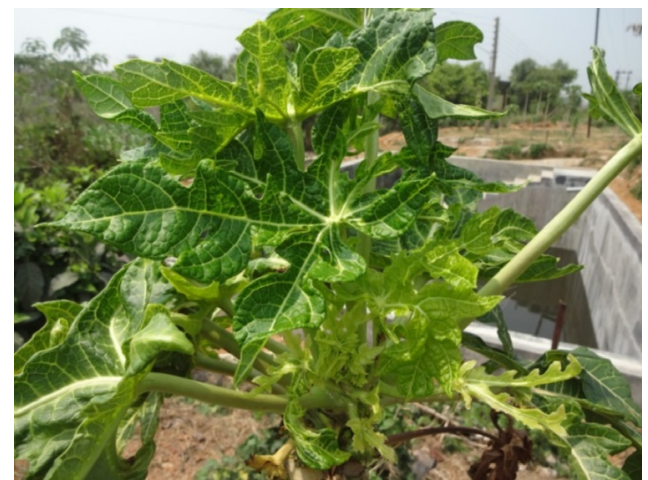

a. Yellowing and vein clearing on young leaves

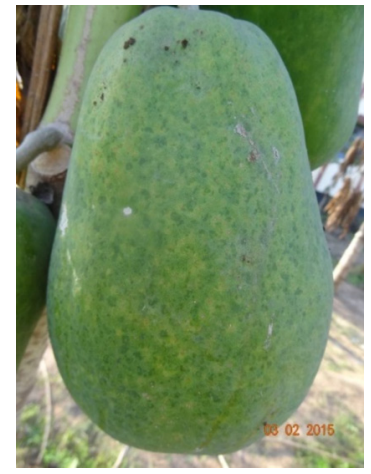

c. Concentric rings and spots or C-shaped markings on fruits

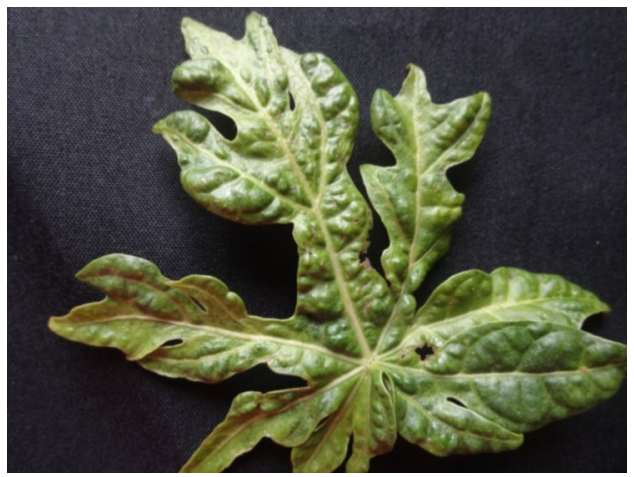

b. Mottling of leaves, severe blistering and leaf distortion

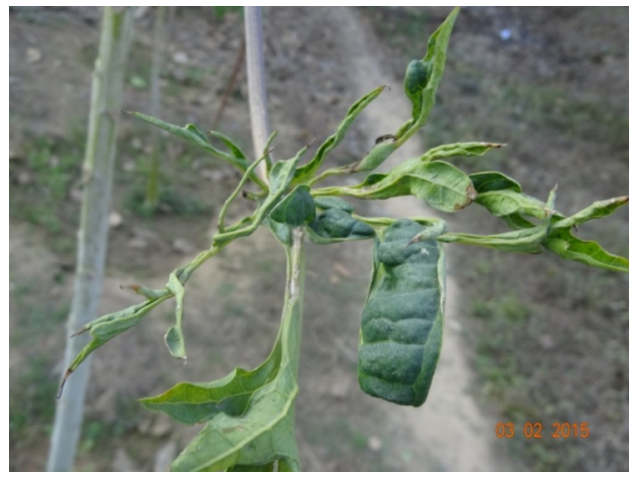

d. Shoe string effect on leaves

Fig. 1. Symptoms of PRSV on papaya at different locations of NEH region

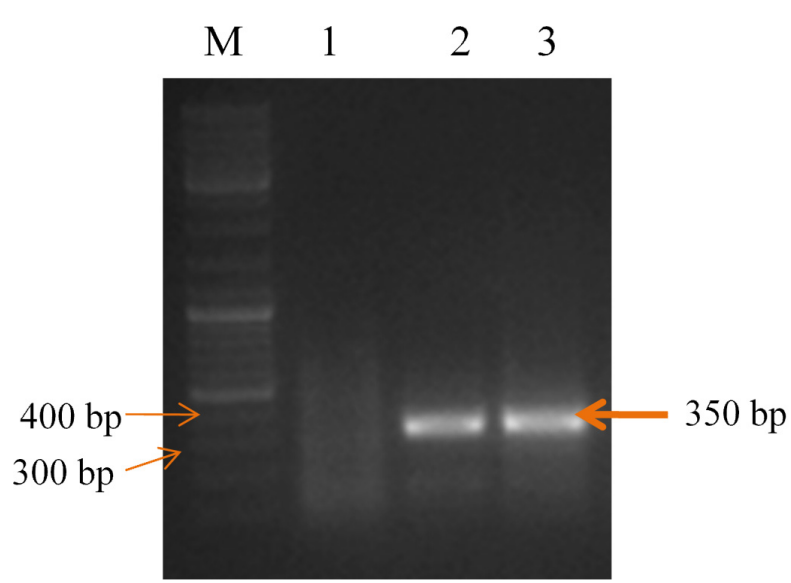

Fig. 2. RT-PCR amplification of symptomatic papaya samples amplifying $350 \mathrm{bp}$ PRSV specific fragment of $\mathrm{Nlb}$ region; M: 100 bp ladder, lane 1: Healthy control, lane 2: papaya sample PRSV-Mnp1, lane 3: papaya sample PRSV-Trp1

designated as PRSV-Mnp1 and PRSV-Trp1 respectively were mechanically transmitted to Chenopodium amaranticolor and papaya varieties (Red Lady, Manipur Local and RCTP-1). Mechanically inoculated papaya plants of all three varieties exhibited symptoms of mottling and shoestring on leaves after 20-24 days postinoculation, however, symptoms were less prominent on the variety RCTP-1. A successful mechanical transmission of PRSV to Carica papaya, cucrbita pepo,
Cucumis stivus, and Citrullus vulgaris was reported by Zetter et al. (1968). Martinez et al. (2014) have also reported the mechanical transmission of PRSV on papaya and Cucurbita pepo with typical symptoms. The symptomatic young leaves in leaf dip preparation under electron microscopy revealed the presence of filamentous flexuous particles of size $800 \times 12 \mathrm{~nm}$ (figure not shown). EM assay further confirmed the association of PRSV with infected papaya samples collected from Tripura and Manipur.

To further confirm the PRSV infection, RT-PCR using primer pair targeting conserved partial NIb region of Potyvirus genome was employed (Zheng et al., 2008). RT-PCR successfully amplified conserved Nib genomic region of PRSV from naturally infected papaya samples collected from Manipur and Tripura. Amplicons of the expected size (350 bp) were obtained from both the infected samples whereas no amplification was observed in healthy plants samples, indicating the viral origin of amplified products (Fig. 2). The PCR products were cloned and sequenced. Analysis of obtained nucleotide sequences of PRSV-Mnp1 and PRSV-Trp1 revealed that both isolates were identical for conserved NIb region (Fig. 3). PRSV-Mnp1 and PRSV-Trp1 shared an identity of 80.2 to $84 \%$ with other PRSV isolates reported from different parts of the world. These isolates had a maximum sequence identity of $84 \%$ with Thai PRSV isolate (AY010722), 83.4\% with other Thai PRSV isolate (AF405531) and 83.1\% with PRSV isolates from Taiwan 


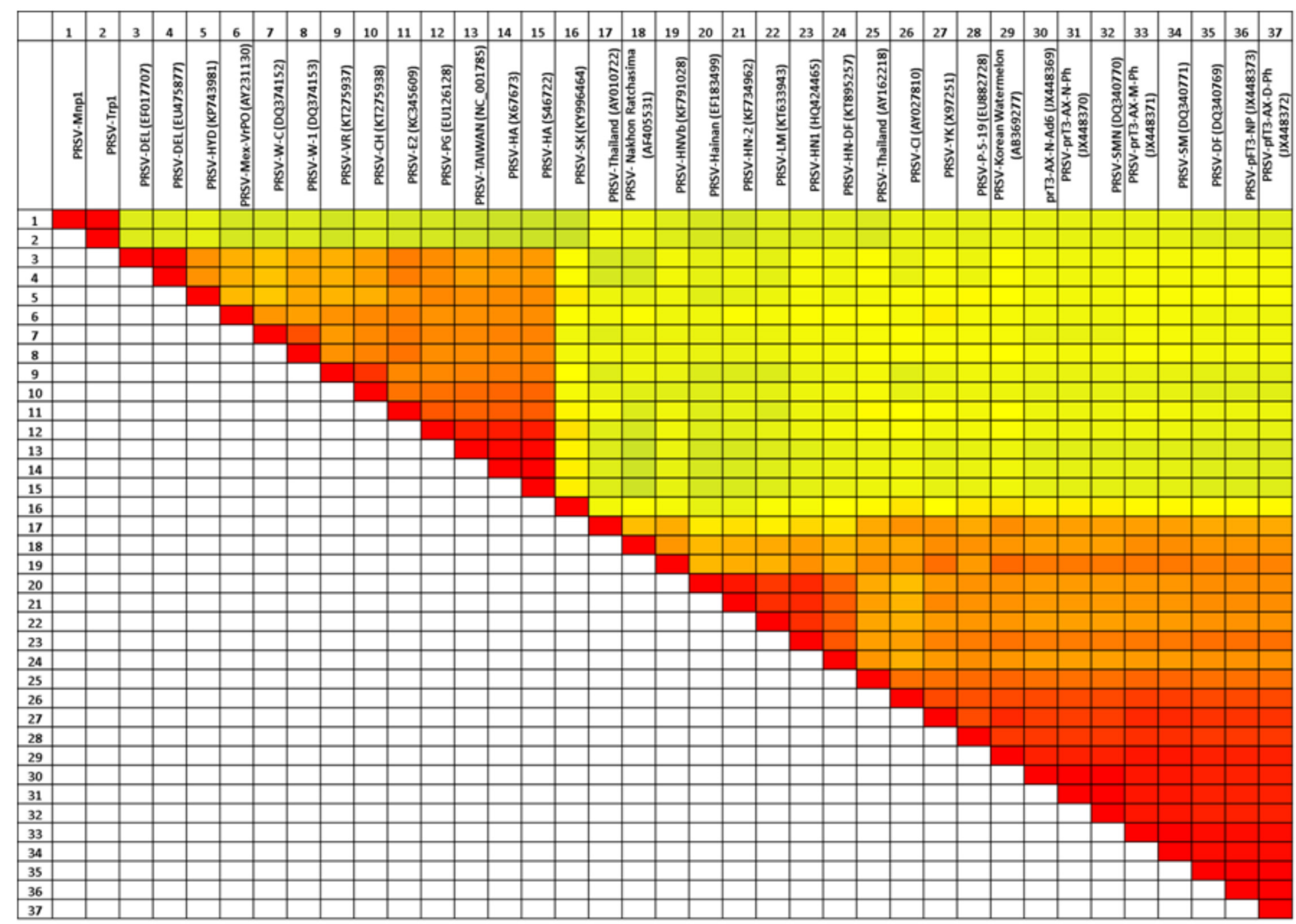

Fig. 3. Two-dimensional colour-coded graphical representation of nucleotide sequence identities of PRSV isolates from NEH region and other parts of the world. The origin of PRSV isolates (numbers mentioned in figure); 1: PRSV-Mnp1 (North East India), 2: PRSV-Trp1 (North East India), 3: India, 4: India, 5: India, 6: Mexico, 7: Brazil, 8: Brazil, 9: Colombia, 10: Colombia, 11: Venezuela, 12: Hawaii, 13: Taiwan, 14: Taiwan, 15: Hawaii, 16: South Korea, 17: Thailand, 18: Thailand, 19: China, 20: China, 21: China, 22: China, 23: China, 24: Taiwan, 25: Thailand, 26: Taiwan, 27: Taiwan, 28: Taiwan, 29: South Korea, 30-37: taiwan. A scale with the percent colour code is presented

and Korea (Fig. 3). Interestingly not many variations for nucleotide sequences of partial NIb genomic region were observed among PRSV isolates originating from different geographical regions of the world. This conserved NIb region could not be used to differentiate among PRSV-P and $\mathrm{W}$ isolates, as the earlier reported PRSV isolates from Delhi (EF017707and EU475877) which were biologically $\mathrm{P}$ and $\mathrm{W}$ type respectively were identical for this genomic region (Fig. 3). Earlier primers derived from conserved NIb region of viral genome were utilized for detection of PRSV from naturally infected papaya samples originating from different locations (Sharma et al., 2004). They also reported the occurrence of PRSV infection from Tamil Nadu based on amplification of CP coding region through RT-PCR. Neighbour joining (NJ) phylogenetic analysis using PRSV isolates (both $\mathrm{P}$ and W biotype) from different parts of the world indicated distinct segregation of Indian PRSV isolates (Fig. 4). Interestingly PRSV isolates from North East India (PRSVMnp1 and PRSV-Trp1) were in separate cluster distinct from group A (Asian PRSV isolates) and group B (American PRSV isolates) as reported by Ortiz-Rojas and Chaves-Bedoya (2017). Indian PRSV population was demonstrated to be genetically distinct as compared to other isolates from different parts of the world (Jain et al., 2004; Srinivasulu and Sai Gopal, 2011). Phylogenetic analysis clearly indicated that PRSV isolates from North East India characterized in this study were genetically distinct from those reported from the North and South India, thus adding another dimension to the genetic profile of Indian PRSV population.

Although widespread occurrence of PRSV from North, Central and South part of India have been reported, there was no conclusive evidence for the association of PRSV with papaya in North East India. The present study conclusively provided the molecular evidence for association of PRSV with ringspot disease of papaya in North East India. A high incidence of PRSV in Manipur and Tripura was recorded in the present study. Characterization of conserved NIb genomic region of PRSV isolates from North East India in present study indicated the existence of genetically district isolates in this region. Further, full genome characterization of PRSV from North East India will shed more light on population genetics of PRSV in India. Although symptoms of PRSV disease on papaya were recorded since long back; to the best of our knowledge, this is the first conclusive 


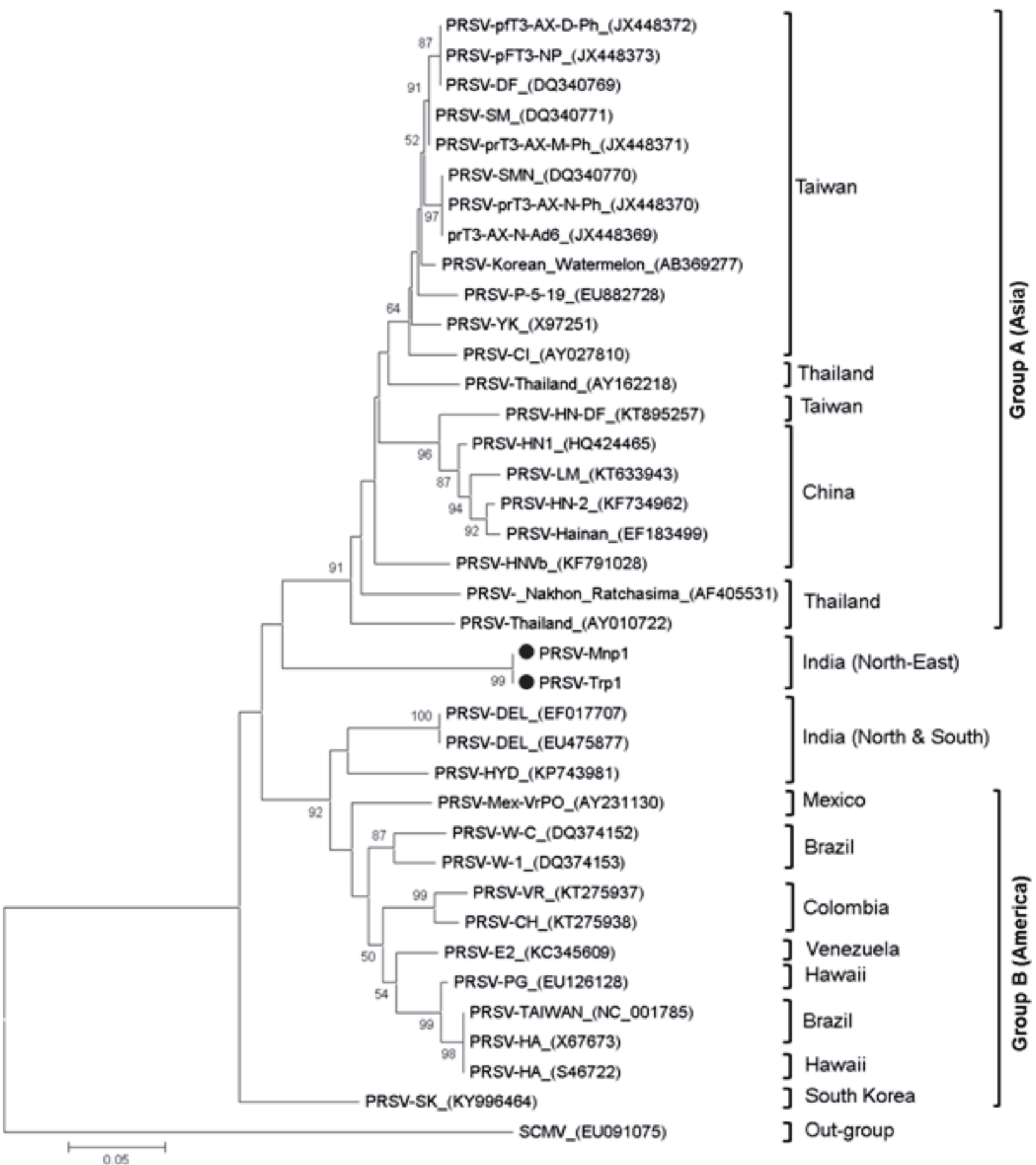

Fig. 4. Neighbor-joining (NJ) phylogentic tree illustrating partial NIb region based relationship of PRSV isolates from NEH region with the PRSV isolates from different geographical regions of world. The evolutionary history was inferred by NJ method based on the Tamura-Nei model. Bootstrap support values from a NJ search with 1000 replicates are shown at the nodes of the branches. Accession number of PRSV isolates is mentioned

molecular evidence for the association of PRSV from $\mathrm{NEH}$ region.

\section{ACKNOWLEDGEMENTS}

Authors are thankful to Joint Director, ICAR RC NEH Manipur Centre and Tripura Centre for providing facilities to conduct this research. This research work was carried out under Institute Project (Project code: IXX13421).

\section{REFERENCES}

Azad MAK, Amin L and Sidik NM (2014). Gene technology for papaya ringspot virus disease management. The Scientific World Journal ID 768038: 1-11.

Brunt A, Crabtree K, Dannwitz M, Gibbs A and Watson L (1996). Viruses of plants. (CAB International, Wallingford, UK) pp. 1484.

Capoor SP and Varma MA (1948). A Mosaic disease of Carica papaya L. in the Bombay province. Curr. Sci. 17: 265-266. 
Fermin G, Castro LT and Tennnat P (2010). CP-transgenic and non-transgenic approaches for the control of Papaya ringspot: current situation and challenges. Tr. PI. J. 4: 115.

Gonsalves D (1998). Control of Papaya ringspot virus in Papaya: A case study. Ann. Rev. Phytopathol. 36: 415-437.

Gulsiri C, Pongsopee A, Mila J, Sakol P and Sunee K (2003). Sequencing and characterization of Thai Papaya ringspot virus isolate Type P (PRSVthP). Science Asia 28: 8994

Hall TA (1999). Bioedit: a user-friendly biological sequence alignment editor and analysis program for windows 95/ 98/NT. Nucleic Acids Symp. Ser. 41: 95-98.

Hussain S and Varma A (1994). Occurrence of papaya ringspot virus from Amritsar (Punjab) India. J. Phytopathol. Res.7: 77-78.

Jain RK, Pappu HR, Pappu SS, Varma AV and Ram RD (1998). Molecular characterization of Papaya ringspot virus isolates from India. Ann. Appl Biol. 32: 413-425.

Jain RK, Sharma J, Sivakumar AS, Sharma PK, Byadgi AS, Verma AK and Varma A (2004). Variability in the coat protein gene of Papaya ringspot virus isolates from multiple locations in India. Arch. Virol. 149: 2435-2442.

Krubphachaya P, Jurícek M and Kertbundit S (2007). Induction of RNA-mediated resistance to papaya ringspot virus type W. J. Biochem. Mol. Biol. 40: 404-411.

Kumar S (2003). Molecular characterization of papaya ringspot virus and expression of its coat protein gene in tobacco. Ph.D Thesis. pp. 77.

Martínez DR, Duarte PSG, Olmedo JG and Figueira AR (2014). Molecular and biological studies of papaya ringspot virus Isolates from Brazil and Cuba. Am. J. Agr. Forest. 2: 209218.

NHB, 2015, Horticultural Statistics at a glance (2016). Horticulture Statistics Division, Department of Agriculture Cooperation and Farmers Welfare, Ministry of Agriculture, Cooperation and Farmers Welfare Government of India.
Ortiz-Rojas LY and Chaves-Bedoya G (2017). Molecular characterization of two papaya ringspot virus isolates that cause devastating symptoms in Norte de Santander, Colombia. Eur. J. Plant Pathol. DOI:10.1007/s10658-0161143-z.

Purcifull De, Edwardson J, Hibert E and Gonsalves D (1984). Papaya ring spot virus CMI/AAB Descriptions of plant viruses No. 292 (CAB International, Wallingford, UK).

Sharma J, Jain RK, Ramaiah M and Varma A (2005). Natural spread of Papaya ringspot virus to new areas: occurrence in Coimbatore, Tamil Nadu. Indian Phytopath. 58: 245-249.

Srinivasulu and SaiGopal DVR (2011). Coat protein sequence comparison of south Indian isolates of papaya ringspot virus with other Indian subcontinent isolates. Phytopathol. Mediterr. 50: 359-367.

Tamura K, Stecher G, Peterson D, Filipski A and Kumar S (2013). MEGA6: Molecular Evolutionary Genetics Analysis Version 6.0. Mol. Biol. Evol. 30: 2725-2729.

Tripathi S, Suzuki J, Ferreira S and Gonsalves D (2008). Papaya ringspot virus - $P$ : characteristics, pathogenicity, sequence variability and control. Mol. Plant Pathol. 9: 269-280.

Varma A. (1988). The economic impact of filamentous plant viruses - The Indian sub-continent. In: The Plant Viruses (Milne RG, ed.), Plenum Press, New York, NY, USA, pp. 371-376.

Yeh SD, Jan FJ, Chiang CH, Doing PJ, Chen MC, Chung PH and Bau HJ (1992). Complete nucleotide sequence and genetic organization of papaya ringspot virus RNA. J. Gen. Virol. 73: 2531-2541.

Zetter EW, Edwardso JR and Purcifull DE (1968). Ultramicroscopic differences in inclusions of papaya mosaic virus and papaya ringspot virus correlated with differential aphid transmission. Phytopathology 58: 332335.

Zheng L, Wayper PJ, Gibbs AJ, Fourment M, Rodoni BC and Gibbs MJ (2008). Accumulating variation at conserved sites in potyvirus genomes is driven by species discovery and affects degenerate primer design. PLOS ONE 3: e1586. 